\title{
Estimation of aerosol particle number distribution with Kalman Filtering - Part 2: Simultaneous use of DMPS, APS and nephelometer measurements
}

\author{
T. Viskari ${ }^{1,2}$, E. Asmi ${ }^{1}$, A. Virkkula ${ }^{1}$, P. Kolmonen ${ }^{1}$, T. Petäjä ${ }^{2}$, and H. Järvinen ${ }^{1}$ \\ ${ }^{1}$ Finnish Meteorological Institute, P.O. Box 503, 00101 Helsinki, Finland \\ ${ }^{2}$ University of Helsinki, Department of Physics, P.O. Box 64, 00014 Helsinki, Finland \\ Correspondence to: T. Viskari (toni.viskari@ fmi.fi) \\ Received: 20 April 2012 - Published in Atmos. Chem. Phys. Discuss.: 31 July 2012 \\ Revised: 7 November 2012 - Accepted: 14 November 2012 - Published: 17 December 2012
}

\begin{abstract}
Extended Kalman Filter (EKF) is used to estimate particle size distributions from observations. The focus here is on the practical application of EKF to simultaneously merge information from different types of experimental instruments. Every $10 \mathrm{~min}$, the prior state estimate is updated with size-segregating measurements from Differential Mobility Particle Sizer (DMPS) and Aerodynamic Particle Sizer (APS) as well as integrating measurements from a nephelometer. Error covariances are approximate in our EKF implementation. The observation operator assumes a constant particle density and refractive index. The state estimates are compared to particle size distributions that are a composite of DMPS and APS measurements. The impact of each instrument on the size distribution estimate is studied. Kalman Filtering of DMPS and APS yielded a temporally consistent state estimate. This state estimate is continuous over the overlapping size range of DMPS and APS. Inclusion of the integrating measurements further reduces the effect of measurement noise. Even with the present approximations, EKF is shown to be a very promising method to estimate particle size distribution with observations from different types of instruments.
\end{abstract}

\section{Introduction}

This is the Part 2 of papers describing the application a data assimilation of in situ multi-instrument aerosol measurements. In Part 1 (Viskari et al., 2012), the Extended Kalman Filter (EKF; Kalman, 1960; for text-book treatment, e.g. Kaipio and Somersalo, 2004) was introduced as a possible method to estimate particle number size distributions with information from multiple instruments. Part 1 covered tests of an EKF implementation with two similar instruments and its statistical validation. Here, the EKF implementation is extended to include observations of different types of instruments.

In situ aerosol measurement instruments can be divided into two categories. Size-segregating instruments measure particle size dependent variables, while integrating instruments measure quantities determined for an ensemble of aerosol particles (McMurry, 2000). Directly combining information from different size-segregating instruments with a mathematical inversion is preferable only if the instruments measure the same quantity as a function of the same variable. Common measurable variables are for example particle electrical mobility, light-scattering intensity or acceleration in a flow field. Even if the instruments were to measure the same quantity, e.g. particle number concentration, an effective comparison of the quantities requires assumptions concerning the possibly size-dependent aerosol properties, such as density or shape factor.

Measurements from different types of instruments can usually be integrated using specific assumptions on particle properties. These assumptions can, for example, be based on experience, specific experiments determining those particle properties, or be obtained by optimization of the match between the instruments. For example, scattering and absorption coefficients can be calculated from the particle size distributions using a Mie scattering code and by 
varying the refractive index. Then the calculated value can be matched with the scattering coefficient measured directly with a nephelometer or the absorption coefficient measured with an absorption photometer (e.g. Hand and Kreidenweis, 2002; Guyon et al., 2003; Virkkula et al., 2006; Müller et al., 2009; Petzold et al., 2009). As an another example, in Pitz et al. (2008), measurements from two different sizesegregating measurement instruments, Differential Mobility Particle Sizer (DMPS) and Aerodynamic Particle Sizer (APS), are combined by modifying the particle density. It is difficult, however, for this approach to properly account for the uncertainties in the different observations. Additionally, this approach can lead to several possible solutions within the observation uncertainties based on the chosen assumptions.

Data assimilation provides an alternative to treat multiinstrument measurements, and can be seen to complement mathematical inversion techniques. The key advantages of Kalman filtering are as follows. First, the measurements are used in a format that is post-processed as little as possible. It is the observation operator that contains the mathematical description of the measurement event. Second, the evolution model of aerosol micro-physics is used to propagate a state from one observation time to the next. This ensures timecontinuity and physical plausibility of the solution as long as the changes in the state are due to the dynamical processes included in the model. Advances in modeling accuracy thus naturally translate into improved state estimates. Finally, different information sources affect the state estimate according to their respective accuracies. The solution is thus statistically optimal. The benefits and current challenges of applying EKF in aerosol physics are discussed in more detail in Part 1.

In Part 1, EKF was introduced and used to merge measurements from two similar instruments. The EKF implementation performed well in comparison to the inversion methods and was able to adjust to the dynamic features of aerosol evolution, for example the nucleation process (Kulmala et al., 2006). The method proved to be sensitive to changes in the size distribution due to external reasons, such as changes in air mass, but also to be able to adjust to those reasonably quickly. The EKF solution appears less noisy than the inversion solution.

This article extends EKF to estimate the particle number size distribution based on information from several different types of instruments. Inclusion of additional trustworthy observations produces a more physically consistent state estimate. The method was tested with size distribution and light scattering measurements from a boreal forest site in the South-Western Finland (Virkkula et al., 2011).

\section{Instruments and their observation operators}

Aerosols, trace gases and meteorological parameters are measured continuously at the SMEAR II (Station for
Measuring Ecosystem-Atmosphere Relations) measurement station in Hyytiälä, South-Western Finland $\left(61^{\circ} 50^{\prime} 47^{\prime \prime} \mathrm{N}\right.$, $24^{\circ} 17^{\prime} 42^{\prime \prime}$ E, 181 m a.m.s.l.; Hari and Kulmala, 2005). The measurements used in this study were a part of the EUCAARI project (Kulmala et al., 2009). Here, the aerosol size distribution is estimated with observations from three instruments: a Differential Mobility Particle Sizer (DMPS), an Aerodynamic Particle Sizer (APS) and a nephelometer. The instruments are described in more detail below.

Kalman filtering requires an observation operator $H$ for each individual instrument. It simulates the measurement event, given the model state vector $\boldsymbol{x}$, and produces the observation counterpart of the observed quantity $\boldsymbol{y}$. The observation modeling is accurate within an error $\varepsilon$, i.e.

$\varepsilon=\boldsymbol{y}-H \boldsymbol{x}$

If we assume for a moment that $x$ is the true state represented in the model grid, the error $\varepsilon$ would consist of the instrument error, the representativeness error due to the finite discretization of $\boldsymbol{x}$, and errors in the observation modeling. The error $\varepsilon$ is nevertheless called the "observation error". Here, the observation error standard deviation is specified as a constant fraction of the observed number concentration.

\subsection{Differential Mobility Particle Sizer (DMPS)}

Differential Particle Mobility Sizer (DMPS) is a sizesegregating instrument that measures aerosol number size distribution based on electrical mobility of the particles. The measurements used here are from a twin-DMPS, which is composed of two DMP instruments measuring different particle size ranges. DMPS I measures the particle number concentration for particle diameters of 3-40 nm and DMPS II for particle diameters of $10-1000 \mathrm{~nm}$. The observation operator for DMPS includes the estimated charging probabilities, transfer functions and size-dependent losses. Details of the DMPS measurement system used are presented in Aalto et al. (2001). The DMPS and the associated observation operator are explained in Part 1 in more detail. As in Part 1, the relative error standard deviation was here set as $15 \%$ for DMPS I and $12 \%$ for DMPS II.

\subsection{Aerodynamic Particle Sizer (APS)}

Size distributions of larger particles, with diameters between 0.5 and $20 \mu \mathrm{m}$, were measured using a TSI Aerodynamic Particle Sizer (APS) model 3321 (Peters and Leith, 2003). The APS determines the particle size using a time-of-flight method. In accelerated flow field, the time taken from the particle to pass between two concurrent laser beams is measured. The resulting particle acceleration rate is converted to a corresponding aerodynamic diameter, which is defined as a particle that has the same settling speed than a spherical particle with the density of $1 \mathrm{~g} \mathrm{~cm}^{-3}$ and thus essentially depends on the particle mass. In the APS, the aerosol- and sheath flow 
rates are 1 and $4 \mathrm{~L}$ per minute, respectively. Inlet line losses in measurements are minimized with vertically positioned moderately heated inlet. With properly calibrated inlet- and aerosol flow rates, the aerodynamic sizing of the APS can be considered accurate. A larger error is expected for the concentration, mainly due to the losses inside the instrument and in the inlet tubes. The instrument losses have been shown to depend on particle size and aerosol phase (Volckens and Peters, 2005) and are thus not easy to correct accurately. When the aerosol concentration is high, additional errors may arise from particle coincidence within the detection time. The APS additionally records the "false" counts from coincidence but these counts are not considered in the size spectrum.

The spherical particle diameter can be converted to a particle aerodynamic diameter, if the density of the particles is known. According to Hinds (1999), assuming that the particles are spherical, the geometric diameter $d_{\mathrm{p}}$ is converted to an aerodynamic particle diameter $d_{\mathrm{a}}$ with

$d_{\mathrm{a}}=d_{\mathrm{p}} \sqrt{\frac{C_{\mathrm{c}}\left(d_{\mathrm{p}}\right)}{C_{\mathrm{c}}\left(d_{\mathrm{a}}\right)}} \sqrt{\frac{\rho_{\mathrm{p}}}{\rho_{0}}}$,

where $\rho_{\mathrm{p}}$ and $\rho_{0}$ is the density for $d_{\mathrm{p}}$ and $d_{\mathrm{a}}$, respectively. Further, for spherical particles, assuming that the particle density equals the density of the bulk material of the particle the mobility diameter equals the geometric diameter (DeCarlo et al., 2004). The slip correction factor $C_{\mathrm{c}}$ remains nearly constant for particle diameters larger than $700 \mathrm{~nm}$ and is thus ignored here. Aerosol density changes both over time and over particle diameter. Here, though, it is approximated as a constant value of $1.5 \mathrm{~g} \mathrm{~cm}^{-3}$ based on Saarikoski et al. (2005) and Kannosto et al. (2008), who examined the density of particles at our measurement site. This approximation was tested and found to be reasonable by varying $\rho_{\mathrm{p}}$ in the EKF implementation by $0.2 \mathrm{~g} \mathrm{~cm}^{-3}$.

The observation operator for the APS instrument $H_{\mathrm{APS}}$ is done by first calculating the geometric diameters from aerodynamic diameters according to Eq. (2). Then the number concentrations are interpolated from the model grid to the geometric diameters of the APS measurement channels. The observation error for APS is specified as $15 \%$ (P. Aalto, personal communication, 2012). The measurement noise is more dominant for small number concentration values and thus will have a larger impact on the APS measurements than on DMPS II measurements. The three lowest APS channels consistently measured smaller number concentrations than the following two channels. This contradicts both our understanding of aerosol size distributions as well as the shape of the observed DMPS size distributions. To mitigate the impact of this apparent systematic error in those three measurement channels, a three time larger observation error $(45 \%)$ was set for their values.

\subsection{Nephelometer}

Measurements of light scattering and absorption by particles at SMEAR II were discussed in detail in Virkkula et al. (2011), here only a brief description is given. For the aerosol optics instruments air is sampled through a $\mathrm{PM}_{10}$ inlet, mounted about $1.5 \mathrm{~m}$ above the roof of the measurement building, approximately $4 \mathrm{~m}$ a.g.l. Total scattering coefficients $\left(\sigma_{\mathrm{SP}}\right)$ and backscattering coefficients $\left(\sigma_{\mathrm{BSP}}\right)$ at $\lambda=$ 450,550 and $700 \mathrm{~nm}$ were measured with a TSI $3 \lambda$ nephelometer (Anderson et al., 1996). The raw $\sigma_{\text {SP }}$ data were corrected for truncation using formulas presented in Anderson and Ogren (1998). The pressure and temperature of the nephelometer were used for correcting the scattering coefficients to 1000 mbar and $0^{\circ} \mathrm{C}$. Heintzenberg et al. (2006) studied the performance of several nephelometers in an intercomparison in Leipzig, Germany, and found that for ambient aerosols the TSI $3 \lambda$ nephelometer uncertainty was approximately $7 \%$.

The scattering coefficients at the nephelometer wavelengths can be determined for a size distribution with

$\sigma_{\mathrm{SP}}(\lambda)=\int Q_{\mathrm{SP}}(\lambda, d, m) \frac{\pi d^{2}}{4} \frac{\partial N(d)}{\partial d} \partial d$

where $Q_{\mathrm{SP}}(\lambda, d, m)$ is the scattering efficiency of particles with a diameter $d, N(d)$ is the particle number concentration as a function of $d$ and a complex refractive index $m=m_{r}+i m_{i}$ at wavelength $\lambda$ (Müller et al, 2011). The scattering efficiencies were calculated using the Mie scattering code of Barber and Hill (1990).

The observation operator $H_{\text {neph }}$ for the nephelometer is the matrix form of the Eq. (3). The observation operator thus contains $Q_{\mathrm{SP}}(\lambda, d, m)$ values for the particle sizes in the model grid. Similarly to $\rho_{\mathrm{p}}, m$ also changes over time and particle diameter. Here, $m_{r}$ was set to a constant value of 1.517 based on Virkkula et al. (2011). Absorption index $m_{i}$ was set to 0.005 . This assumption was found to be reasonable by repeating the EKF implementation tests with perturbed $m_{r}$ and $m_{i}$ (by about 0.1 and 0.01 units, respectively). Note that $m$ presented in Virkkula et al. (2011) is the calculated value for the wavelength of $550 \mathrm{~nm}$ (A. Virkkula, personal communication, 2012). In reality there is a negative correlation between $m_{r}$ and $\lambda$. Thus the refractive index should be slightly smaller for the wavelength of $450 \mathrm{~nm}$ and slightly larger for the wavelength of $700 \mathrm{~nm}$. For simplicity here we used the same refractive index for all wavelengths. The relative error for the nephelometer measurements was set to $7 \%$.

\section{Multi-instrument EKF implementation}

The EKF implementation is explained in Part 1. Here it is only briefly summarized. 


\subsection{Extended Kalman Filter (EKF)}

The EKF estimates the state of the aerosol system in two steps. First, both the background state and the error covariance matrix are propagated from the observation time $k-1$ to $k$. Then, the new state is expressed as

$\boldsymbol{x}_{a, k}=\boldsymbol{x}_{k}+\mathbf{K}_{k}\left(\boldsymbol{y}_{k}-H \boldsymbol{x}_{k}\right)$,

where $\boldsymbol{x}_{k}$ is the background state, $\boldsymbol{x}_{a, k}$ is the new state estimate and $\boldsymbol{y}_{k}$ is the observed state. The Kalman gain $\mathbf{K}_{k}$ is

$\mathbf{K}_{k}=\mathbf{B}_{k} \mathbf{H}^{T}\left[\mathbf{H B}_{k} \mathbf{H}^{T}+\mathbf{O}_{k}\right]^{-1}$.

The background and observation error covariance matrices, $\mathbf{B}_{k}$ and $\mathbf{O}_{k}$, respectively, are crucial as their properties determine how the information sources are weighted. Both the non-linear and tangent-linear observation operators $H$ and $\mathbf{H}$, respectively, are applied here. Essentially, the state estimate is obtained by correcting the time-evolved state with the latest observations based on their reliabilities.

In this study, the error covariance matrices are simplified (Part 1). For the instruments, the matrices are assumed diagonal, i.e. measurement errors are assumed independent between channels and instruments. For the background error covariance, the standard deviations are artificially kept at $20 \%$ of the number concentration of the background state in order to prevent the EKF implementation from ever considering the background state as more reliable than the observations. In this artificial error inflation, the error correlations between different particle sizes are preserved in the B-matrix.

The inclusion of the APS measurements requires two practical additions to the EKF implementation. For the APS, there is a possibility for several adjacent empty measurement channels amongst channels that do observe particles. This may cause instability in the computation of the inverse matrix using singular value decomposition (SVD). Basic Tikhonov regularization (Tarantola, 2004) was used to solve this problem. A very small value, $10^{-6} \mathrm{\#} \mathrm{cm}^{-3}$, was added to the diagonal of $\mathbf{H B H}^{T}+\mathbf{O}$. The impact of the added diagonal value is then reduced by ignoring the very smallest eigenvalues.

The number concentrations measured with the APS are generally very small and can undergo large relative changes over consecutive measurement times. This, along with the simplifications made in the current EKF implementation, can cause the update to a number concentration value to be larger than the initial number concentration in that size bin. To avoid negative number concentrations, an ad hoc limit to the reduction of particle size number concentration was set to $90 \%$ in maximum.

\subsection{University of Helsinki Multi-component Aerosol (UHMA) model}

University of Helsinki Multi-component Aerosol (UHMA; Korhonen et al., 2004) model was used to propagate the background state. It is a size-segregating box model that includes the nucleation, condensation, coagulation and deposition processes. The model time step used here is $10 \mathrm{~s}$. Three ambient vapours, sulphuric acid and two organic vapours, affected the state evolution in this implementation. For each time step the ambient vapour concentrations were estimated from measurements. The model and the assumed ambient conditions are more thoroughly explained in Part 1. We stress that both the particle density and the refraction index were assumed to be constant in time and over particle diameter in the observation operator. The EKF implementation was found to be more sensitive to changes and uncertainties in the number concentration measurements. Thus the particle number concentration is both the control and forecast variables here.

The choice of the model grid resolution impacts the EKF implementation in a few ways. On one hand, the increased model grid resolution significantly improves the modeling of condensation process of newly formed particles (Leppä et al., 2011). On the other hand, the larger number of model grid points exponentially increases the computational cost of the model due to the coagulation process. For the EKF implementation, the increase in computational cost is even larger due to the already increased computational cost of the implementation (note, that the dimension of the "B"-matrix increases and the time evolution of the "B"-matrix is performed column by column). Here, the resolution of the model grid is chosen to be computationally feasible, but still sufficient to effectively depict the condensation processes in the smallest particle sizes. The diameter size range in the model grid is $1.5 \mathrm{~nm}-20 \mu$ with 60 discrete size bins at a logarithmically even spacing.

\section{Results and analysis}

The results and analysis are provided for 7 May 2007, which contains several aerosol events. In Part 1, this day was thoroughly studied in light of DMPS measurements only, focusing on how the EKF handles aerosol size distribution features and events. For consistency, the same date was used here. The results for this date were also found to be well representative for the period April-May 2007 in the Hyytiälä station (Part 1).

It is informative to compare the EKF implementation with alternative methods to combine measurements from different instruments. Particle size distributions measured by TwinDMPS and APS have been effectively combined by varying particle density until the measurements are in agreement in the overlapping measurement range (Pitz et al., 2008). The resulting particle number size distribution will closely fit the observations at each measurement time, but will not necessarily be continuous over time. Distributions estimated with $\mathrm{EKF}$, in contrast, will be more continuous over time, but not necessarily closely fit the observations at each measurement time. As there two approaches differ on how closely they 


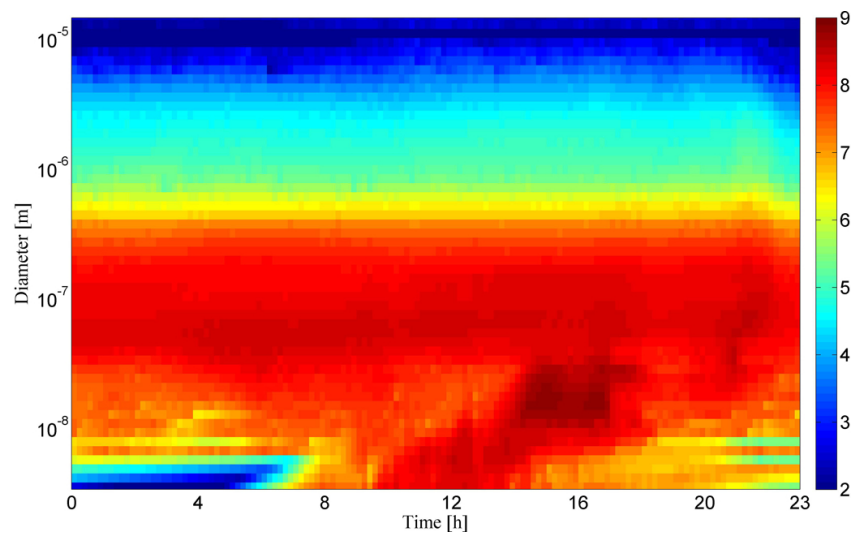

Fig. 1a. Particle number size distribution obtained with EKF using DMPS and APS observations $\left(x_{\mathrm{DA}}^{N}\right)$ on 7 May 2007 from SMEAR II in Hyytiälä, Finland. Note that the particle number concentrations are only presented from $10^{2}$ to $10^{9} \mathrm{~m}^{-3}$. The color bar values are given as exponents of 10 .

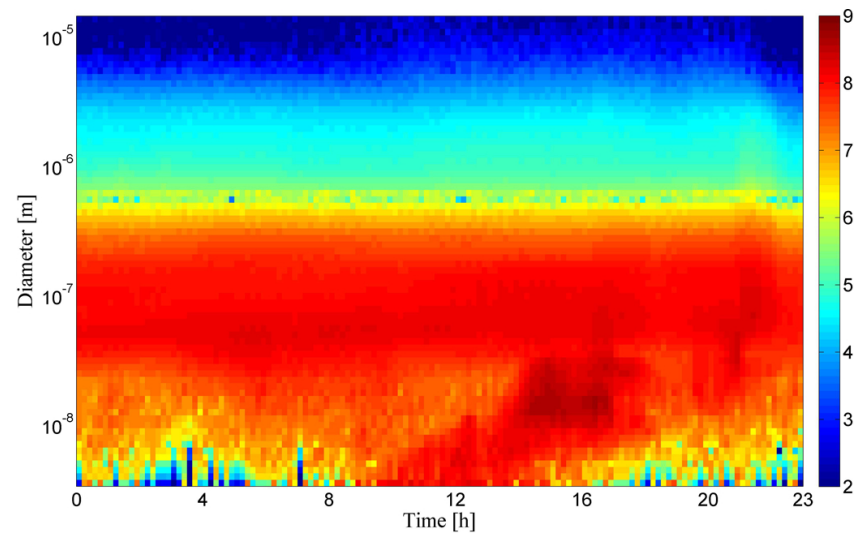

Fig. 1b. As in Fig. 1a, but for combined state $\left(x_{\text {com }}^{N}\right)$.

must fit the observations at each measurement time, it was not considered sensible to currently compare their results.

Instead, a combined particle number size distribution is created here by calculating the corresponding geometric particle sizes from the aerodynamic particle sizes, using inverted particle number size distribution calculated with a leastsquare non-negative pseudo-inverse for the Twin-DMPS up to $700 \mathrm{~nm}$ and continuing with APS measurements beyond $700 \mathrm{~nm}$. The size distribution is then interpolated to a logarithmically evenly spaced grid with 74 size bins. The smallest (largest) particle diameter in the new grid is $3.5 \mathrm{~nm}(15 \mu \mathrm{m})$. This method was used in Virkkula et al. (2011). These particle number size distributions will be referred to as $\boldsymbol{x}_{\mathrm{com}}^{N}$.

\subsection{Inclusion of the APS measurements}

A particle number size distribution estimated by EKF with DMPS and APS observations is here referred to as $\boldsymbol{x}_{\mathrm{DA}}^{N}$.

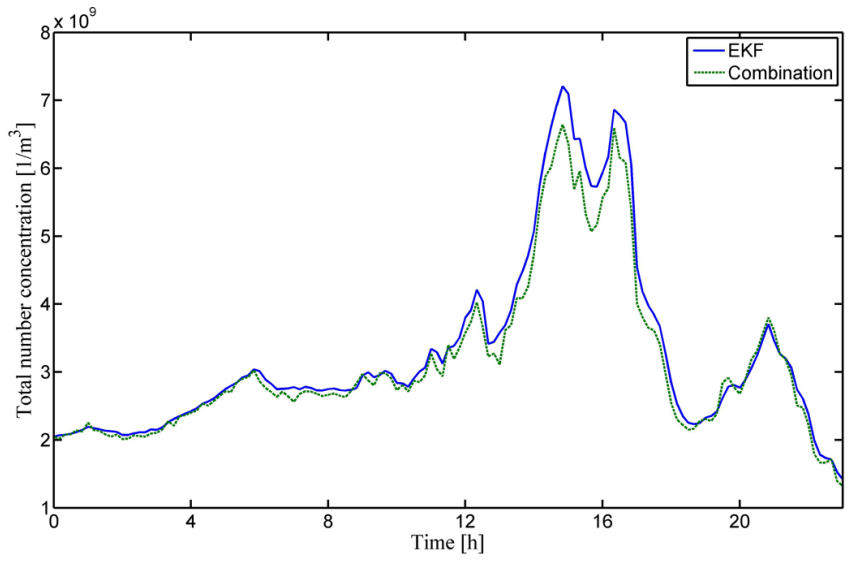

Fig. 1c. The total number concentrations for particles larger than $3 \mathrm{~nm}$ for $\boldsymbol{x}_{\mathrm{DA}}^{N}$ (blue, solid) and $\boldsymbol{x}_{\text {com }}^{N}$ (green, dashed).

The estimated particle number size distribution $\left(\boldsymbol{x}_{\mathrm{DA}}^{N}\right.$; Fig. 1a) and the combined observed particle number size distribution $\left(x_{\text {com }}^{N}\right.$; Fig. 1b) for 7 May 2007 are shown in Fig. 1. All diameters used in this article are defined as the Stokes diameter of a particle. For the most part $\boldsymbol{x}_{\mathrm{DA}}^{N}$ and $\boldsymbol{x}_{\mathrm{com}}^{N}$ appear to evolve broadly the same way. In the overlapping size range of $600-800 \mathrm{~nm}, \boldsymbol{x}_{\mathrm{com}}^{N}$ is discontinuous over particle diameter while $\boldsymbol{x}_{\mathrm{DA}}^{N}$ is more continuous both over particle diameter and time. This is due to the inclusion of both DMPS II and APS measurements in the overlapping measurement size range. For particles smaller than $10 \mathrm{~nm}$ as well as larger than $6 \mu \mathrm{m}$, $\boldsymbol{x}_{\mathrm{DA}}^{N}$ is also smoother than $\boldsymbol{x}_{\mathrm{com}}^{N}$. This is because the EKF effectively filters out random measurement errors. Note that the resolution in Fig. 1a corresponds to the UHMA model grid while in Fig. $1 \mathrm{~b}$ it is the combined measurement grid. In Fig. 1c is presented the total particle number concentration for both size distributions over time. The total number concentrations follow each other rather closely, but the EKF solution has generally somewhat more particles. This is not surprising, as in the number space the submicron aerosol population dominates and the inclusion of APS data has only a minor role. This agreement was already established in Part 1 (Viskari et al., 2012).

Figure $1 \mathrm{~b}$ shows that the number concentrations within the APS measurement range are much smaller than those in the DMPS measurement range. Thus DMPS measurements dominate both the size distribution and the total number concentration. In contrast, the volume concentration, which is the sum of particle volume within a size bin, will be dominated by particles larger than $100 \mathrm{~nm}$. The volume concentration distributions are presented in Fig. 2. The volume concentration for $\boldsymbol{x}_{\mathrm{DA}}^{N}$ is referred to as $\boldsymbol{x}_{\mathrm{DA}}^{V}$ (Fig. 2a) and for $\boldsymbol{x}_{\text {com }}^{N}$ as $\boldsymbol{x}_{\text {com }}^{V}$ (Fig. 2b). They resemble each other, even though it is important to note that differences between $\boldsymbol{x}_{\mathrm{DA}}^{N}$ and $\boldsymbol{x}_{\mathrm{com}}^{N}$ lead to larger differences between $\boldsymbol{x}_{\mathrm{DA}}^{V}$ and $\boldsymbol{x}_{\text {com }}^{V}$ as the particle sizes increases. The most notable difference between $x_{\mathrm{DA}}^{V}$ 


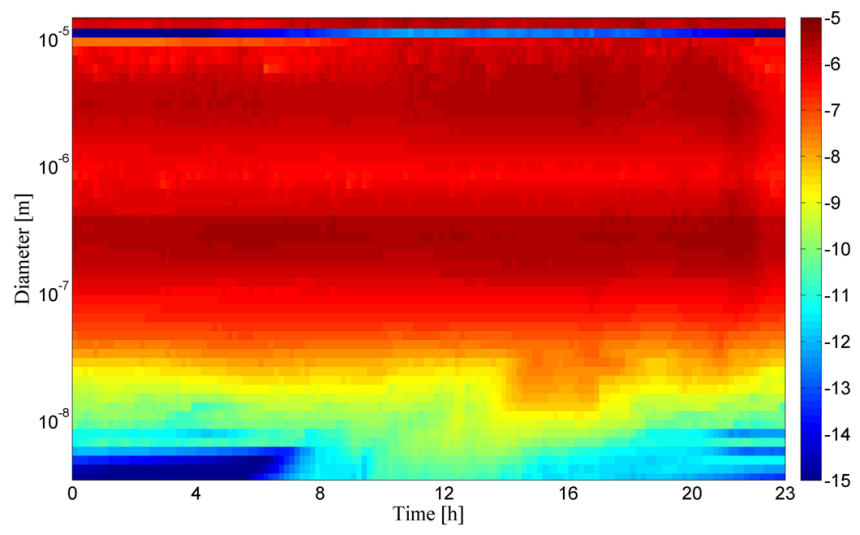

Fig. 2a. Particle volume size distribution obtained with EKF using DMPS and APS observations $\left(x_{\mathrm{DA}}^{V}\right)$ on 7 May 2007 from SMEAR II in Hyytiälä, Finland. Note that the particle volume concentrations are only presented from $10^{-15}$ to $10^{-5} \mathrm{~cm}^{3} \mathrm{~m}^{-3}$. The color bar values are given as exponents of 10 .

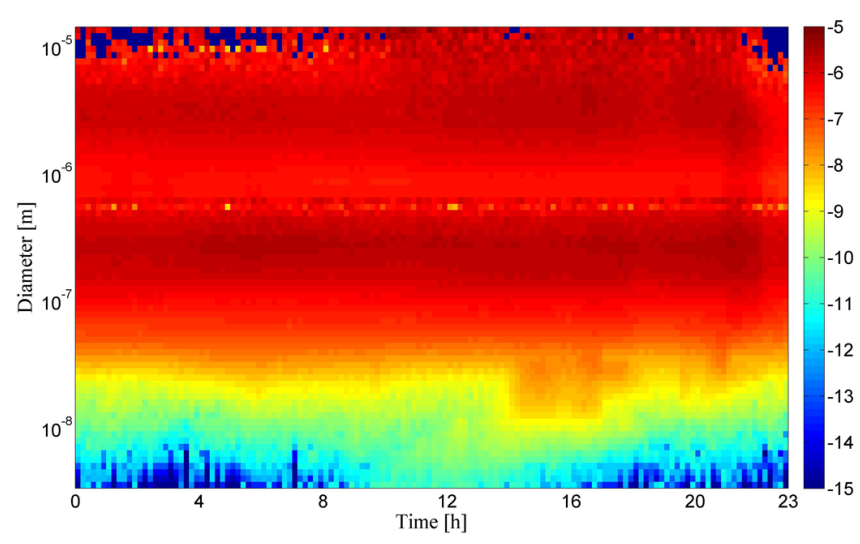

Fig. 2b. As in Fig. 2a, but for the combined state $\left(\boldsymbol{x}_{\mathrm{com}}^{V}\right)$.

and $\boldsymbol{x}_{\mathrm{com}}^{V}$ is in particle sizes larger than $10 \mu \mathrm{m}$. For $\boldsymbol{x}_{\mathrm{DA}}^{V}$, the particle volume concentration becomes very small for particles near size $10 \mu \mathrm{m}$, and then increases again for particles larger than $13 \mu \mathrm{m}$. For $\boldsymbol{x}_{\mathrm{com}}^{V}$, instead, the particle volume concentrations in size ranges larger than $8 \mu \mathrm{m}$ evolve erratically. This is caused by the measured very small number concentrations in those particle sizes. The total volume concentration for both size distributions over time are presented in Fig. 2c. Total number concentration values are dominated by particles smaller than $100 \mathrm{~nm}$ (Fig. 1a), but the total volume concentrations values are dominated by particles larger than $100 \mathrm{~nm}$ (Fig. 2a). The total volume concentrations vary more over subsequent observation times than the total number concentrations. This indicates that the measurement noise has more impact for the particle sizes larger than $100 \mathrm{~nm}$. The smoothing due to EKF is also more visible in the total volume concentrations than in the total number concentrations.

Since the focus here is on the inclusion of the APS measurements to the EKF, further results will be presented

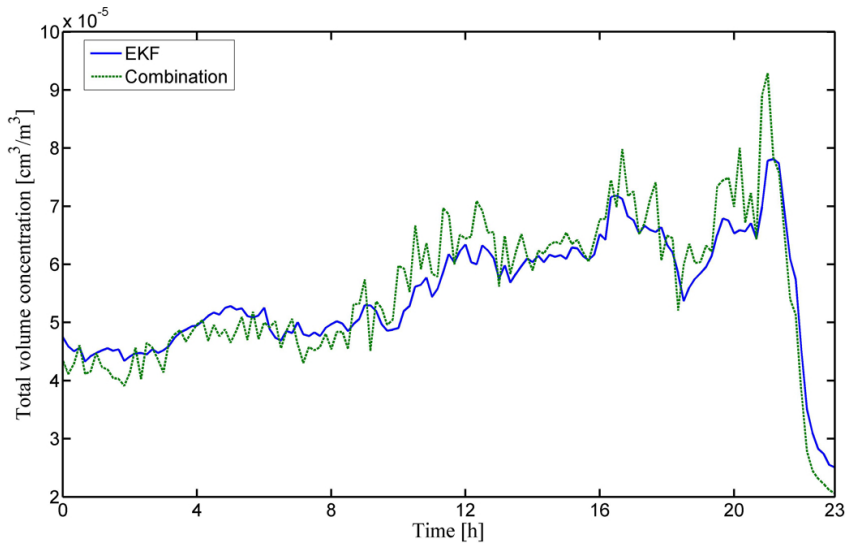

Fig. 2c. The total volume concentrations for particles larger than $3 \mathrm{~nm}$ for $\boldsymbol{x}_{\mathrm{DA}}^{V}$ (blue, solid) and $\boldsymbol{x}_{\mathrm{com}}^{V}$ (green, dashed).

concerning the volume size distribution unless mentioned otherwise.

According to Fig. 2a and b, there is a large difference between $\boldsymbol{x}_{\mathrm{DA}}^{V}$ and $\boldsymbol{x}_{\mathrm{com}}^{V}$ for particle diameters larger than $8 \mu \mathrm{m}$. This is due to several reasons. The APS is less accurate for larger particle sizes (Volckens and Peters, 2005), which partially explains the apparently random evolution of particles larger than $8 \mu \mathrm{m}$ in Fig. 2b. Additionally, EKF constrains state estimates over particle diameter based on the aerosol dynamical processes. As the impact of the aerosol dynamical processes decreases on the particle size distribution with increase in particle diameter, $\boldsymbol{x}_{\mathrm{DA}}^{N}$ and $\boldsymbol{x}_{\mathrm{DA}}^{V}$ are only weakly constrained over particle size for particles larger than $4 \mu \mathrm{m}$. Finally, due to the very small number concentrations of particles larger than $4 \mu \mathrm{m}$, the error is Poissonian rather than Gaussian. This can cause distortions in the state estimate. This size range is thus sensitive for the measurements, the model as well as the error assumptions. Due to these reasons, the state estimate is not reliable for particle sizes larger than $4 \mu \mathrm{m}$, as evidenced for instance by the discontinuity over particle sizes at $10 \mu \mathrm{m}$ visible in Fig. 2a.

It is important to note that although both DMPS and APS measure number concentration, the measurement principles are different. Thus the results cannot be directly compared even for measurements in the same particle sizes. Figure 3 illustrates this by presenting the volume concentration for both $\boldsymbol{x}_{\mathrm{DA}}^{V}$ and its corresponding values in the DMPS II and APS measurement channels according to $H$ as well as for the actual measurements over particle sizes $30 \mathrm{~nm}-10 \mu \mathrm{m}$ at 12:00 Local time (LT). Note that in order to compare DMPS II measurements with APS measurements, DMPS II measurements are shown as a function of the characteristic diameters, i.e. the diameter of a single charge particle most likely measured in the set electrical field. APS measurements are also given as similar diameters calculated from aerodynamic diameters using a constant density of $1.5 \mathrm{~g} \mathrm{~cm}^{-3}$. 

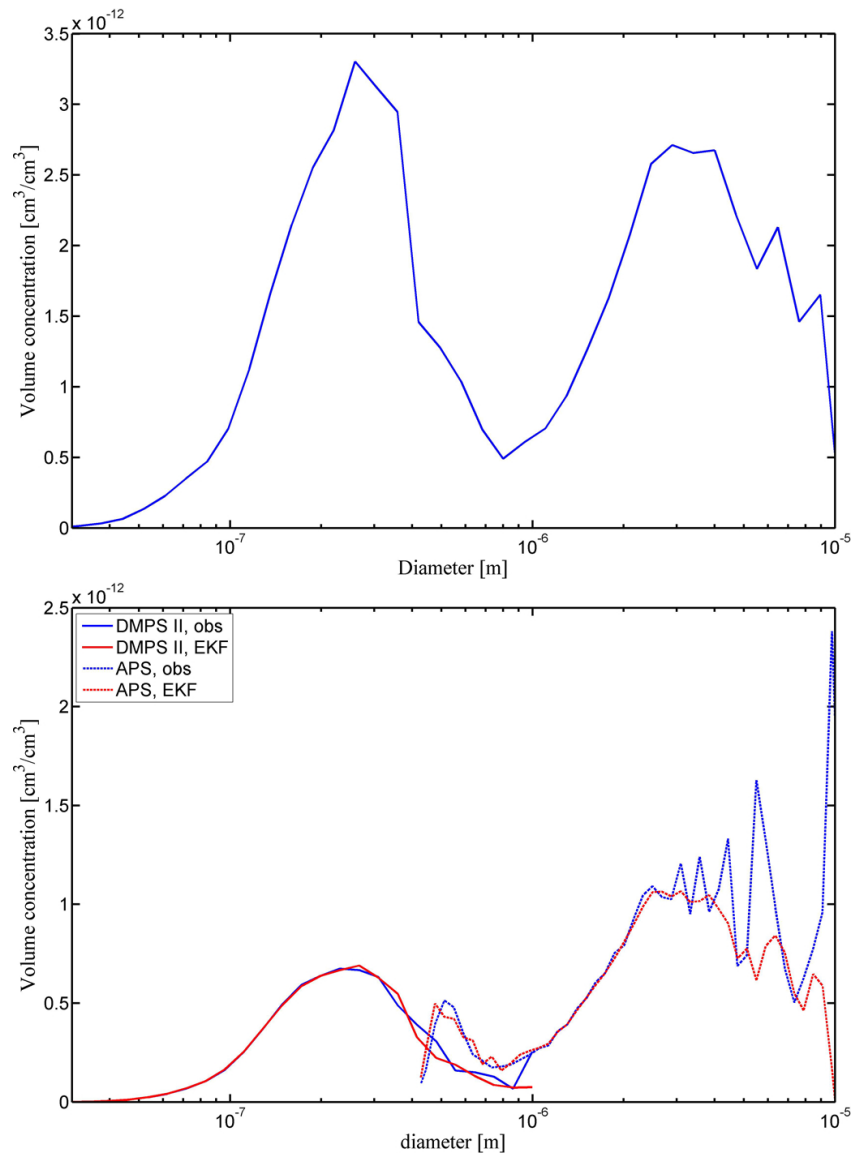

Fig. 3. The estimated volume concentration size distribution in 300$2000 \mathrm{~nm}$ at 12:00, 7 May 2010 from SMEAR II in Hyytiälä, Finland (top panel). The observations (blue) and corresponding estimate calculated with $H$ (red) from $300 \mathrm{~nm}$ to $10 \mu \mathrm{m}$ for DMPS II (solid) and APS (dashed) from 12:00 on 7 May 2010 from SMEAR II in Hyytiälä, Finland (bottom panel). Volume concentrations are on the $\mathrm{y}$-axis $\left[\mathrm{cm}^{3} \mathrm{~cm}^{-3}\right]$ and particle diameter on the $\mathrm{x}$-axis $[\mathrm{m}]$.

Figure 3 demonstrates that the raw measurements have very different values even in the overlapping measurement range of 400-1000 $\mathrm{nm}$ due to measuring different variables. The values calculated from $x_{\mathrm{DA}}^{V}$ fit both DMPS II and APS measurements relatively well for particles smaller than $4 \mu \mathrm{m}$. For particles larger than $4 \mu \mathrm{m}$, the APS measurements become discontinuous over particle diameter and largely differ from the estimate. Due to the differences in the measurement values, a reliable statistical comparison between DMPS and APS measurements is difficult. Fundamentally the EKF implementation performs similarly when merging information from two DMPS instruments or from DMPS and APS instruments. For DMPS I and DMPS II, EKF estimates a state that is statistically at least as reliable as common numerical methods (Part 1). Hence, we assume the method to be valid also over the majority of the APS measurement area.

\subsection{Inclusion of the nephelometer measurements}

The scattering coefficient measured by the nephelometer at a given wavelength is representative of the entire particle size distribution. Scattering of electromagnetic radiation in the visible wavelength range mainly originates from particles larger than about $100 \mathrm{~nm}$ and is dominated by particles in the range of 300-700 nm. For example, approximately $90 \%$ of the integrated light scattering at Hyytiälä was due to submicron particles (Virkkula et al., 2011). Consequently, the inclusion of the nephelometer measurements has the largest impact in this size range. EKF nevertheless spreads the scattering information to the particle size distribution based on their contribution to the scattering. A particle number size distribution estimated with DMPS, APS and nephelometer observations is referred here to as $\boldsymbol{x}_{\mathrm{DAN}}^{N}$.

The applied nephelometer measurements are from ten minute intervals with timestamps matching the DMPS and APS measurements. As mentioned in Sect. 2.3, the sensitivity of the EKF implementation to $m$ was tested by perturbing these values (not shown). The change of refractive index had a notable impact on $x_{\text {DAN }}^{N}$ in particle size range of $300-700 \mathrm{~nm}$, but only a limited effect beyond those particle sizes. Uncertainties related to the size-segregated measurements still dominate in the affected size range despite the chosen value for $m_{r}$.

The particle volume concentration distribution $\left(\boldsymbol{x}_{\mathrm{DAN}}^{V}\right)$ and the total volume concentration for the estimated particle size distribution over time are shown in Fig. 4. It is relatively similar to $\boldsymbol{x}_{\mathrm{DA}}^{V}$, except $\boldsymbol{x}_{\mathrm{DAN}}^{V}$ estimates slightly smaller values than $x_{\mathrm{DA}}^{V}$ for particle sizes larger than $100 \mathrm{~nm}$. In Fig. 5 is shown the observed scattering $\left(\sigma_{\text {obs }}\right)$ as well as the calculated scattering from $\boldsymbol{x}_{\mathrm{DA}}^{N}\left(\sigma_{\mathrm{DA}}\right)$, from $\boldsymbol{x}_{\mathrm{DAN}}^{N}\left(\sigma_{\mathrm{DAN}}\right)$ and from $\boldsymbol{x}_{\mathrm{com}}^{N}$ $\left(\sigma_{\mathrm{com}}\right)$ for three wavelengths, $450 \mathrm{~nm}, 550 \mathrm{~nm}$ and $700 \mathrm{~nm}(\mathrm{a}$, $\mathrm{b}$ and c, respectively), for 08:00-18:00 LT. At $450 \mathrm{~nm}$, is $\sigma_{\mathrm{obs}}$ larger than either $\sigma_{\mathrm{DA}}$ or $\sigma_{\mathrm{DAN}}$ and at $700 \mathrm{~nm} \sigma_{\mathrm{obs}}$ is smaller than either $\sigma_{\mathrm{DA}}$ or $\sigma_{\mathrm{DAN}}$. At $550 \mathrm{~nm}, \sigma_{\mathrm{obs}}, \sigma_{\mathrm{DA}}$ and $\sigma_{\mathrm{DAN}}$ are roughly equal. For 450 and $550 \mathrm{~nm}, \sigma_{\mathrm{DA}}$ is closer to $\sigma_{\mathrm{obs}}$ than $\sigma_{\text {com }}$. For wavelengths $550 \mathrm{~nm}$ and $700 \mathrm{~nm}, \sigma_{\text {DAN }}$ is closer to $\sigma_{\mathrm{obs}}$ than $\sigma_{\mathrm{DA}}$. For wavelength $450 \mathrm{~nm}, \sigma_{\mathrm{DA}}$ is generally slightly closer to $\sigma_{\text {obs }}$ than $\sigma_{\text {DAN }}$.

The relationship between the observed and estimated scattering coefficients is different between the wavelengths. The nephelometer measurements thus affect the state estimate in opposite ways, with the observations for $450 \mathrm{~nm}$ tending to increase, and for $700 \mathrm{~nm}$ tending to decrease the estimated scattering coefficient. These differences between the estimated and observed scattering coefficients are partially caused by the assumption that the refractive index is the same for all wavelengths. For example increasing the scattering coefficient slightly for radiation wavelength of $450 \mathrm{~nm}$ would also increase estimated scattering coefficient for that wavelength.

By comparing different calculated scattering coefficients, it is notable that $\sigma_{\text {DAN }}$ is smoother than $\sigma_{\mathrm{DA}}$, which in turn 

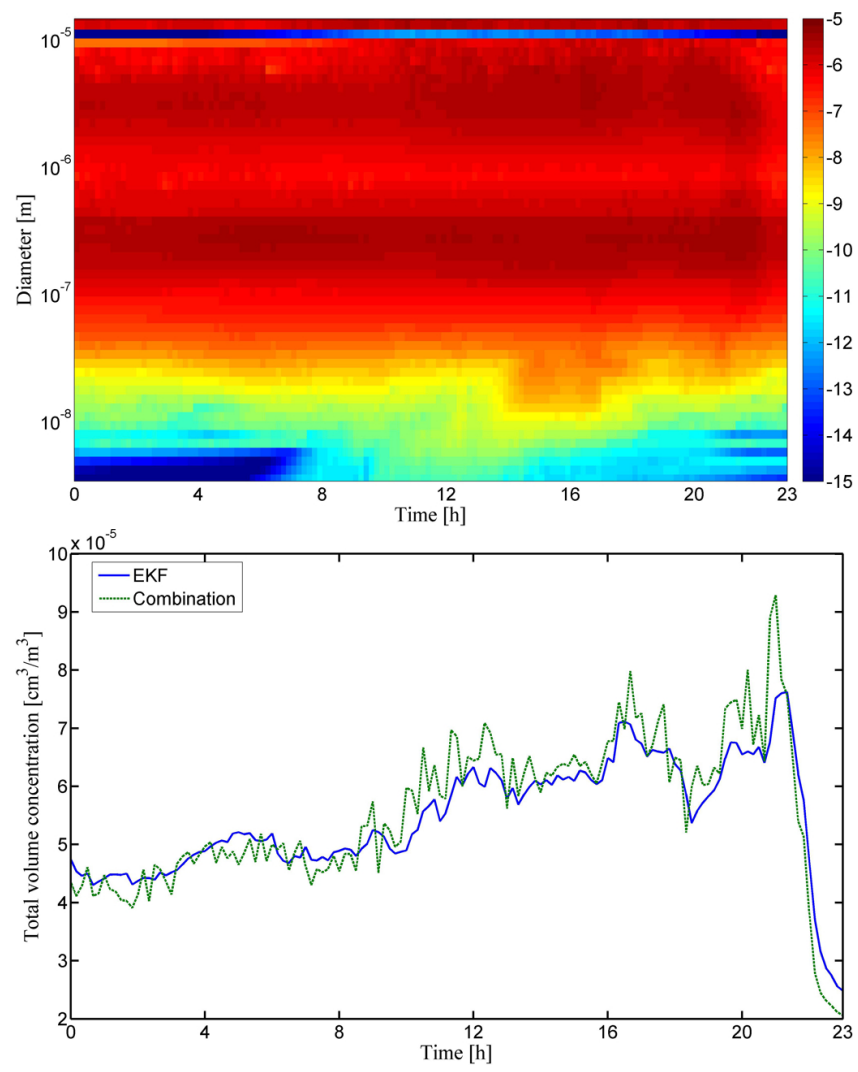

Fig. 4. Particle volume size distribution obtained with EKF using DMPS, APS and nephelometer observations $\left(\boldsymbol{x}_{\text {DAN }}^{V}\right)$ on 7 May 2007 from SMEAR II in Hyytiälä, Finland (top panel). Note that the particle number concentrations are only presented from $10^{-15}$ to $10^{-5} \mathrm{~cm}^{3} \mathrm{~m}^{-3}$. The color bar values are given as exponents of 10 . The total volume concentrations for particles larger than $3 \mathrm{~nm}$ for $\boldsymbol{x}_{\mathrm{DAN}}^{V}$ and $\boldsymbol{x}_{\mathrm{com}}^{V}$ (bottom panel).

is smoother than $\sigma_{\text {com }}$. This indicates that the $x_{\text {DAN }}^{N}$ is temporally more continuous than $\boldsymbol{x}_{\mathrm{DA}}^{N}$ in particle size range of $300-700 \mathrm{~nm}$. It should be noted that it is logical for the inclusion of the nephelometer measurements to produce estimates with scattering coefficients closer to the observed values. The determination of ambient aerosol number size distribution is rather complicated in the $300-700 \mathrm{~nm}$ size range due to, for instance multiple charging that affect inversion for DMPS and fast acceleration for APS. The scattering coefficient, on the other hand, is dominated by the particles in this size range. Thus, the implementation of EKF to retrieve consistent results from a combination of number size distribution measurements and light scattering could result in improvements in data quality.

The scattering coefficients of the background state prior to the inclusion of observations (not shown) differ little from those of the state estimate. Nevertheless, the inclusion of the nephelometer measurements affect the particle size distribution as a whole over a longer period of time (Fig. 4) by acting as an additional constraint to the state estimates.
During the sudden changes in the aerosol number size distributions after 17:00 LT (Fig. 1b), there are momentary differences between $\boldsymbol{x}_{\mathrm{DA}}^{V}$ and $\boldsymbol{x}_{\mathrm{DAN}}^{V}$. Figure 6a presents $\boldsymbol{x}_{\mathrm{DA}}^{V}$ and $\boldsymbol{x}_{\mathrm{DAN}}^{V}$ as well as their corresponding values in the DMPS II and APS measurements channels according to $H$ (see Eq. 1) in addition to the actual measurements in particle sizes $30 \mathrm{~nm}-10 \mu \mathrm{m}$ at 16:00 LT. For comparison, in Fig. $6 \mathrm{~b}$ the same distributions are shown for 21:00 LT. In Fig. 6a the differences between the two state estimates are very small and both are close to the observed state. In Fig. $6 \mathrm{~b}$, though, there is a noticeable difference between the two estimates, with $\boldsymbol{x}_{\mathrm{DA}}^{V}$ being closer to the DMPS observations. This difference between $\boldsymbol{x}_{\mathrm{DA}}^{V}$ and $\boldsymbol{x}_{\mathrm{DAN}}^{V}$ decreases substantially in 20-30 min.

The reason for the difference between $\boldsymbol{x}_{\mathrm{DA}}^{V}$ and $\boldsymbol{x}_{\mathrm{DAN}}^{V}$ in Fig. $6 \mathrm{a}$ is that the nephelometer and the DMPS/APS are in disagreement when the sudden change in particle size distributions occurs despite measuring the same aerosol size distribution. If the nephelometer time stamps were reduced by 20 min, for instance from 21:00 to 20:40 LT, $\boldsymbol{x}_{\text {DA }}^{V}$ and $\boldsymbol{x}_{\text {DAN }}^{V}$ are much closer to each other. Thus most likely explanations for this are that the timestamps for the instruments are not synchronized or that the air volume observed by the nephelometer does not for some reason instantly change according to the general air mass. The difference, however, allows for the study of how the nephelometer observations impact the state estimate when there is a large difference between state observed by the nephelometer compared to the state observed by DMPS and APS. These results show that the nephelometer measurements can have a major impact on the state estimate in particle sizes larger than $100 \mathrm{~nm}$. Further analysis indicates that the nephelometer measurements have the largest impact on the state estimate when the size distribution undergoes a major change in particle sizes larger than $100 \mathrm{~nm}$. During those times the inclusion of the nephelometer measurements accelerates or decelerates the adaptation of the state estimate to the changes in the observations.

\subsection{Analysis increments due to the measurements}

The EKF implementation used here merges information from three different types of instruments. As each instrument observes a different quantity, direct comparison of the observed values is not straightforward. In other words, the difference $\boldsymbol{y}_{k}-H \boldsymbol{x}_{k}$ in Eq. (5) is in the observation space and specific for each instrument. However, $\mathbf{K}_{k}\left(\boldsymbol{y}_{k}-H \boldsymbol{x}_{k}\right)$ in Eq. (5), referred to as "the increment", is a model space quantity and independent of the type of the instrument. Therefore it only depends on definition of the model space (i.e. on the choice of the dynamical evolution model). The increment is an update vector added to the background state and is an expression of the observation impact on the background state. Two factors determine the increment: (1) the difference between the background state $\boldsymbol{x}_{k}$ and the observations $\boldsymbol{y}_{k}$, and (2) the relative weight given to the observations and the background, as contained in $\mathbf{K}_{k}$. As all the increments are calculated for 
a)

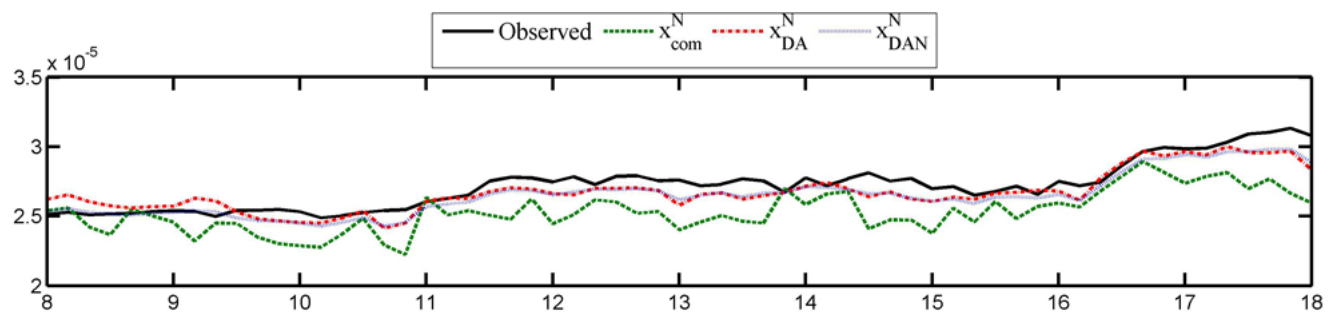

b)
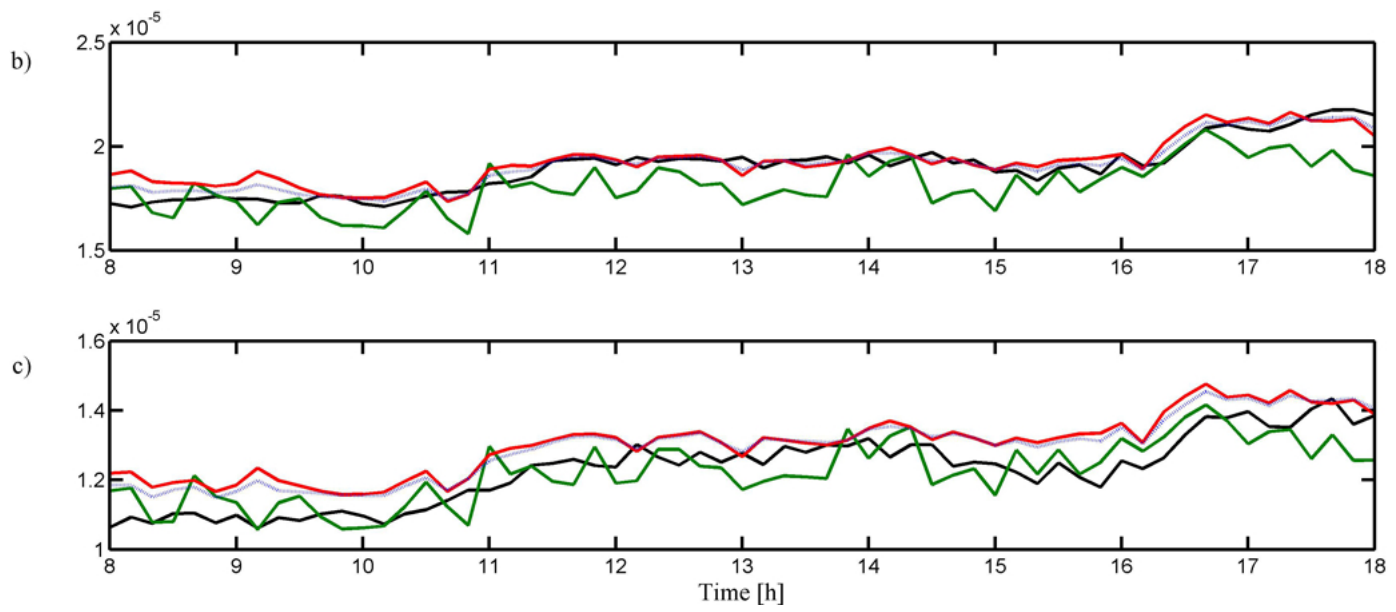

Fig. 5. The observed scattering ( $\sigma_{\mathrm{obs}}$; black, solid), the scattering calculated from $\boldsymbol{x}_{\mathrm{DA}}^{N}\left(\sigma_{\mathrm{DA}}\right.$; red, dot-dashed), from $\boldsymbol{x}_{\mathrm{DAN}}^{N}\left(\sigma_{\mathrm{DAN}}\right.$; blue, dotted) and from $\boldsymbol{x}_{\mathrm{com}}^{N}\left(\sigma_{\mathrm{com}}\right.$; green, dashed) for wavelengths 450,550 and $700 \mathrm{~nm}$ (a, b and $\mathbf{c}$, respectively).

the background particle number size distribution, increments from different instruments are thus comparable. For clarity, the increments were scaled with $\boldsymbol{x}_{k}$

$\delta \boldsymbol{x}_{k}=\mathbf{K}_{k}\left(\boldsymbol{y}_{k}-H \boldsymbol{x}_{k}\right) \boldsymbol{x}_{k}^{-1}$,

where $\delta \boldsymbol{x}_{k}$ is the relative increment at time $k$. We note that this approach will emphasize somewhat more the positive than the negative increments during the statistical analysis presented here.

The relative increments for DMPS I, DMPS II, APS and the nephelometer $\left(\delta \boldsymbol{x}_{\mathrm{DI}}, \delta \boldsymbol{x}_{\mathrm{DII}}, \delta \boldsymbol{x}_{\mathrm{APS}}\right.$ and $\delta \boldsymbol{x}_{\mathrm{neph}}$, respectively) as well as the sum of all the individual increments $\left(\delta \boldsymbol{x}_{\text {tot }}\right)$ over the particle size distribution and averaged for 7 May 2007 are shown in Fig. 7. Firstly, we note that the size ranges where instruments overlap, that is, $10-40 \mathrm{~nm}$ for DMPS I and II as well as $450-1000 \mathrm{~nm}$ for DMPS II, APS and nephelometer, the increments due to different instruments are generally opposite. This is due to the fact the estimate is a compromise between the different measured size distributions. Secondly, we note that in the particle sizes 3$50 \mathrm{~nm}$ and $0.5-13 \mu \mathrm{m}$, the mean $\delta \boldsymbol{x}_{\text {tot }}$ has large positive values. This indicates that in those particle sizes $x_{k}$ systematically differs from $\boldsymbol{y}_{k}$ either due to model or measurement deficiency. And finally, we note that the average increments are non-zero even beyond the measurement ranges of individual instruments. This is due to effect of the "B"-matrix.
For example, the average $\delta \boldsymbol{x}_{\mathrm{APS}}$ has values already at $200 \mathrm{~nm}$ although its measurement range limited to $300-2000 \mathrm{~nm}$.

Figure 7 presents the mean increments for the whole day. Figure 8 splits the mean increment to four separate time windows:

- In the time interval 00:00-09:00 LT, the aerosol system is quasi-stationary (Fig. 8a).

- In the time interval 09:00-17:00 LT, particle formation affects the size distribution (Fig. 8b).

- In the time interval 17:00-19:00 LT, there is a sudden change in the size distribution due to some external reasons (Fig. 8c).

- In the time interval 19:00-23:00 LT, there is a possible recovery phase (Fig. 8d).

In all windows, for particle sizes $7-13 \mu \mathrm{m}$ there is a large average positive $\delta \boldsymbol{x}_{\mathrm{APS}}$, which dominates $\delta \boldsymbol{x}_{\text {tot }}$. This corresponds to the measured particle number concentration (Fig. 2b) which is increasing over most of the time. Similarly, new particle formation results in a large $\delta \boldsymbol{x}_{\mathrm{DI}}$, and consequently $\delta \boldsymbol{x}_{\text {tot }}$, for particle sizes smaller than $10 \mathrm{~nm}$ (Fig. $8 \mathrm{a}$ and $b$ ). In both cases the increment is affected by the measurement noise and small number concentrations.

Also common in all windows is that the increments for two separate instruments do not agree in the overlapping measurement ranges either for DMPS I and II $(10-40 \mathrm{~nm})$ or 

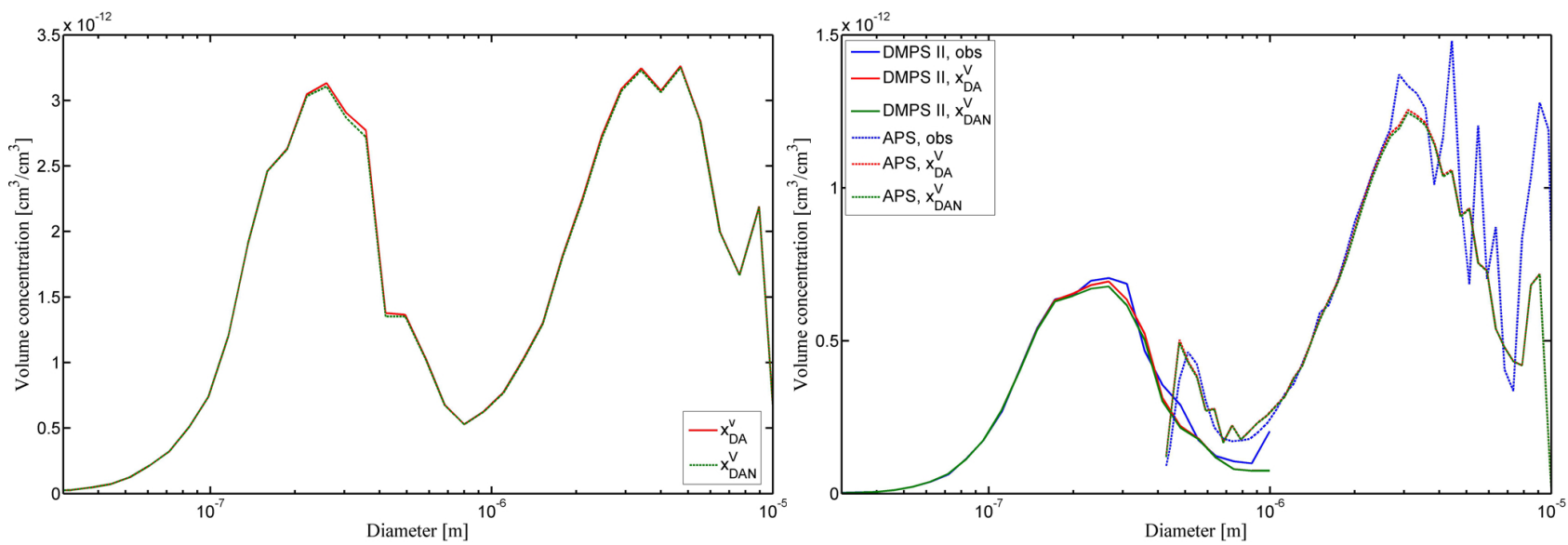

Fig. 6a. (Above) The estimated volume concentration size distribution and (Below) the observations (blue), $\boldsymbol{x}_{\mathrm{DA}}^{V}$ (red) and $\boldsymbol{x}_{\mathrm{DAN}}^{V}$ (green) for both DMPS II (solid) and APS (dashed) for particle sizes $300 \mathrm{~nm}-10 \mu \mathrm{m}$ from 16:00 on 7 May 2010 from SMEAR II in Hyytiälä, Finland. Volume concentrations are on the $\mathrm{y}$-axis $\left[\mathrm{cm}^{3} \mathrm{~cm}^{-3}\right]$ and particle diameter on the $\mathrm{x}$-axis $[\mathrm{m}]$.
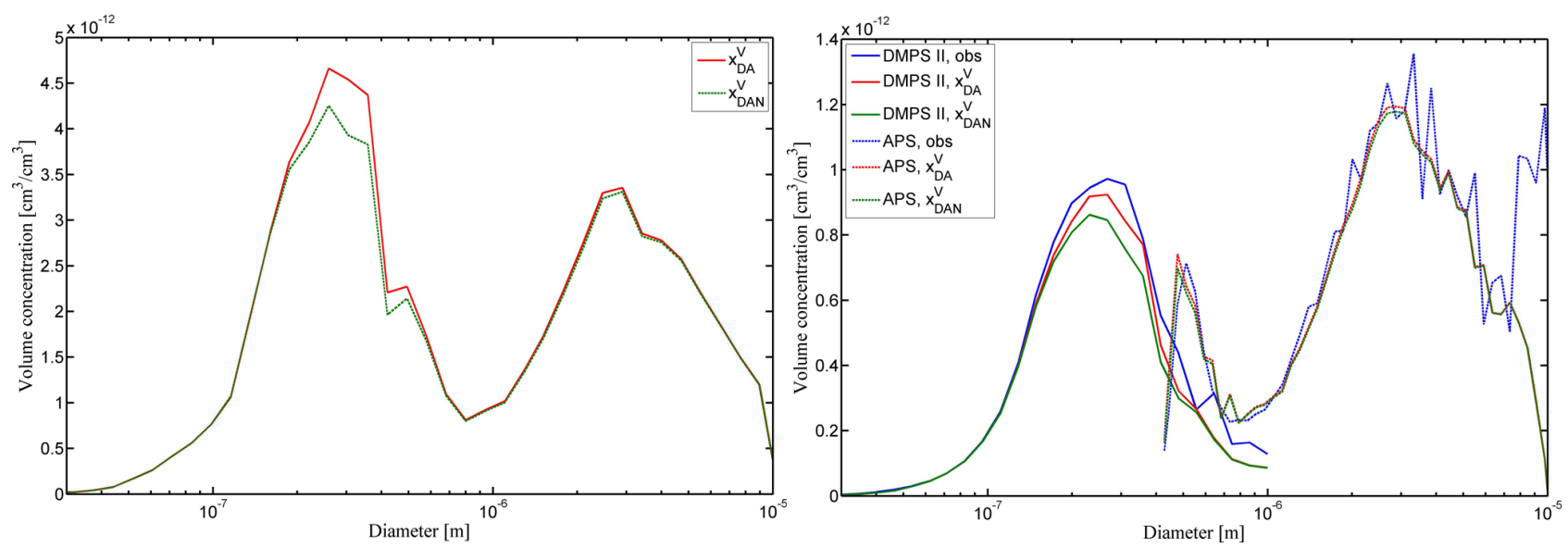

Fig. 6b. Same as Fig. 6a, but for 21:00 LT.

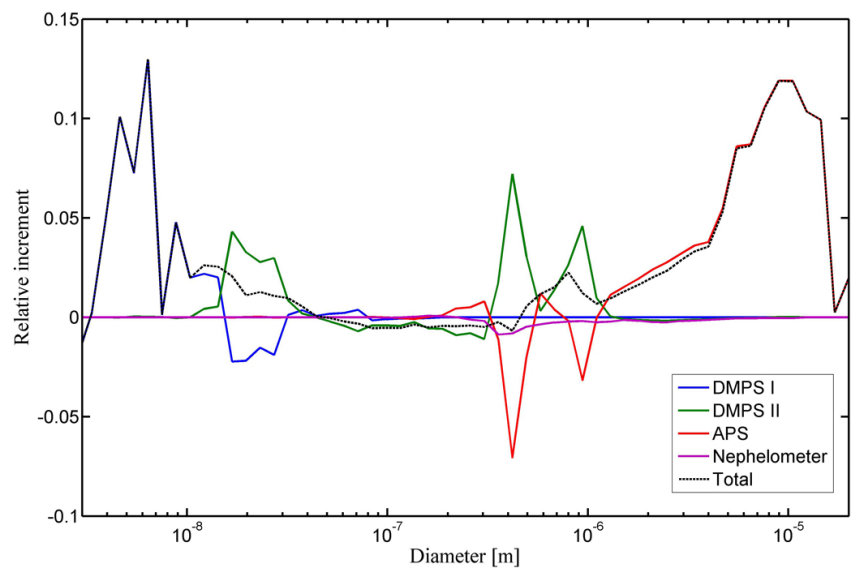

Fig. 7. The average relative increment for DMPS I (blue), DMPS II (green), APS (red), nephelometer (purple) as well as the average total relative increment (black, dashed) on 7 May 2007. for DMPS II and APS (400-1000 nm). Large differences between measurements for same particle sizes result in large differences between the respective increments. For DMPS I and II, there is a systematic difference between the average $\delta \boldsymbol{x}_{\mathrm{DI}}$ and $\delta \boldsymbol{x}_{\mathrm{DII}}$ in all time windows, with $\delta \boldsymbol{x}_{\mathrm{DII}}$ always leaning more towards the positive values compared to $\delta \boldsymbol{x}_{\mathrm{DI}}$. This indicates that DMPS II observes higher particle number concentrations than DMPS I in the overlapping measurement range. In Fig. 8 a the initial new particle formation can be seen from the positive average $\delta \boldsymbol{x}_{\mathrm{DI}}$ and $\delta \boldsymbol{x}_{\mathrm{DII}}$ in the overlapping measurement range. Finally, the change in air mass can be seen in Fig. 8c) as the sudden decrease in number concentrations below $50 \mathrm{~nm}$ particles (Fig. 1b) leads to a negative average $\delta \boldsymbol{x}_{\mathrm{DI}}$ and $\delta \boldsymbol{x}_{\mathrm{DII}}$ in those particle sizes.

In the overlapping measurement range of DMPS II and APS, for particle sizes of $400-500 \mathrm{~nm}$ the average $\delta \boldsymbol{x}_{\text {DII }}$ and $\delta \boldsymbol{x}_{\mathrm{APS}}$ are opposite with respect to the background state, with $\delta \boldsymbol{x}_{\text {DII }}$ having a positive value. This large difference between 

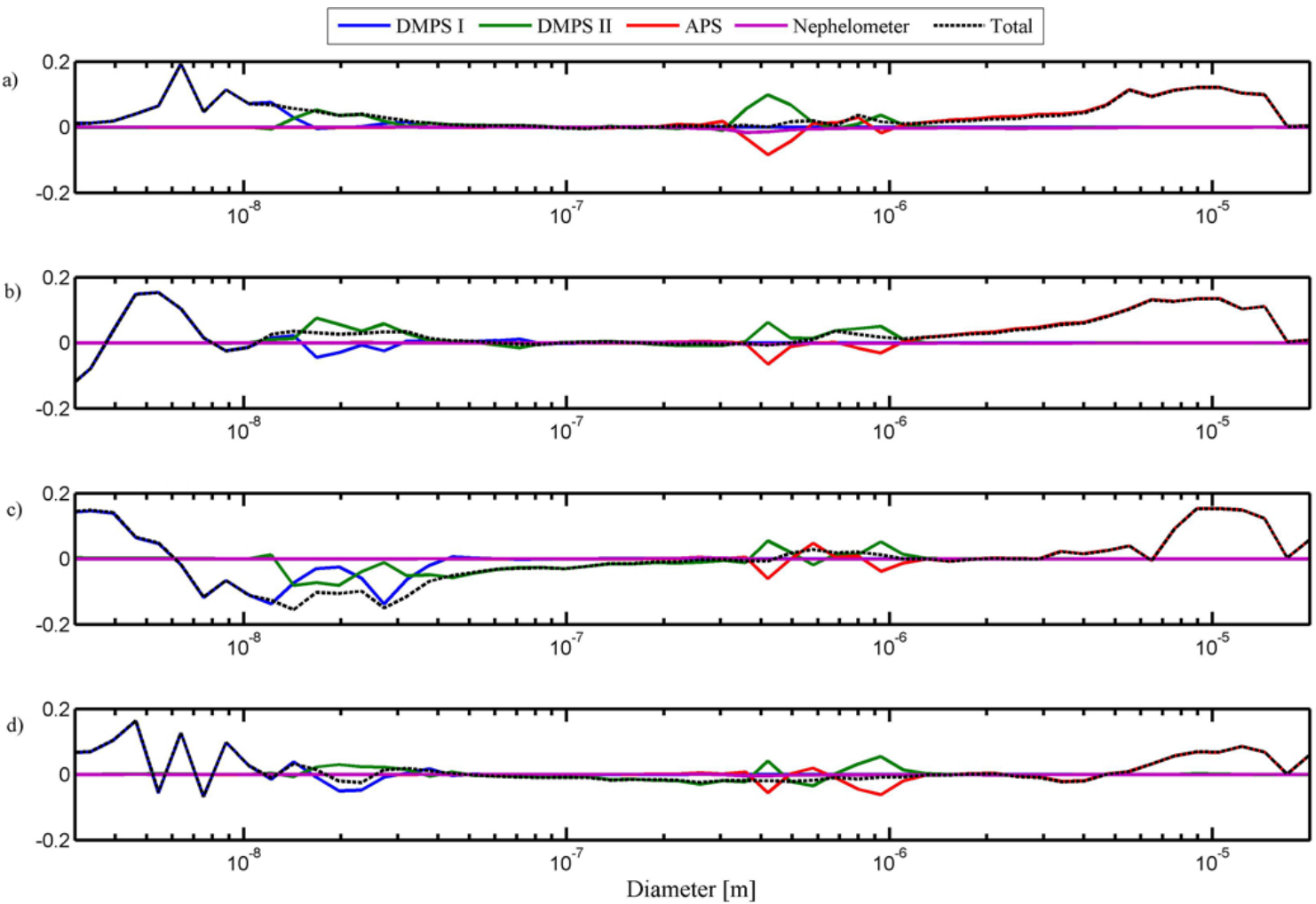

Fig. 8. The average relative increment for DMPS I (blue), DMPS II (green), APS (red), nephelometer (purple) as well as the average total relative increment (black, dashed) for time windows (a) 00:00-09:00, (b) 09:00-17:00, (c) 17:00-19:00 and (d) 19:00-23:00 on 7 May 2007.

the increments is due to the tendency of the APS to underestimate the number concentrations at those particle sizes. For particle sizes of $900-1000 \mathrm{~nm}, \delta \boldsymbol{x}_{\mathrm{DII}}$ is always more towards positive values than $\delta \boldsymbol{x}_{\mathrm{APS}}$. This is likely due to the unreliability of DMPS II measurements in those particle sizes. For particle sizes of 500-900 nm, the average differences between $\delta \boldsymbol{x}_{\mathrm{DII}}$ and $\delta \boldsymbol{x}_{\mathrm{APS}}$ have very little in common between time windows. This indicates that the differences between the measurements are either random or due to changes in the parameters, e.g. particle density, as those parameters can change over time. Changes in the parameters affect the observation operators, which would in turn would affect how observations from different instruments compare to each other.

The average $\delta \boldsymbol{x}_{\text {neph }}$ is notable only in Fig. 8a, where it has slight negative values over most of the size distribution, especially in the particle sizes $300-700 \mathrm{~nm}$. This is due to the observed scattering coefficients being generally smaller than the calculated scattering coefficients, especially for the wavelength of $700 \mathrm{~nm}$. This is likely due to both the choice of $m$ as well as inaccurate observations. Otherwise, the average $\delta \boldsymbol{x}_{\text {neph }}$ is small, which indicates that the calculated scattering coefficients are close to the observed scattering coefficients. This supports the chosen values of $m$.

The average $\boldsymbol{x}_{\text {tot }}$ in individual time windows is nicely related to different events. In Fig. 8b, the nucleation event is visible for particle sizes smaller than $20 \mathrm{~nm}$. In Fig. 8c, the change in air mass results negative $\delta \boldsymbol{x}_{\text {tot }}$ in average in particle sizes 7-200 nm. In Fig. 8d, the second change in air mass is visible as the average negative $\delta \boldsymbol{x}_{\text {tot }}$ in particle sizes 100 $1000 \mathrm{~nm}$.

\section{Conclusions}

The Extended Kalman Filter (EKF) implementation, introduced in Part 1 and extended in Part 2, was used to simultaneously estimate particle size number distributions based on measurements from DMPS, APS and nephelometer. The first two instruments are size-segregating instruments that measure different aerosol variables in different size ranges. The last one is an integrating instrument that measures a single quantity for the whole particle size distribution. The motivation for the research was to study the ability of the EKF to merge information from multiple information sources, especially in the measurement ranges where several instruments overlap, and to establish the ability of EKF to estimate size distributions from multiple observations.

The EKF implementation was tested by first including observations from DMPS and APS and then also observations from nephelometer. The results were compared to a state directly obtained as a combination of DMPS and APS measurements. The state estimated by EKF was found to 
be continuous in time as well as across the overlapping size range of DMPS and APS for particles smaller than $\sim 4 \mu \mathrm{m}$. This continuity was constrained by the known dynamical processes and information from previous measurements. However, in the case of a sudden change in the system, the information from the previous measurements causes the state estimate to adapt to the new state with a slight lag. The state estimate is not reliable for particle sizes larger than $\sim 4 \mu \mathrm{m}$ due to problems with the dynamical processes, measurement accuracies and non-Gaussian uncertainties in those particle sizes.

The inclusion of the nephelometer observations reduced particle number concentration somewhat and smoothed the estimate in particle sizes larger than about $100 \mathrm{~nm}$. Scattering coefficients calculated from the EKF state estimates were closer to the observed scattering coefficients than those calculated from the states obtained as a combination from DMPS and APS observations. This favors the use of EKF implementation in the future for providing consistent estimates for optical properties from measured particle size distributions. The results were only presented for 7 May 2007, which in Part 1 was established as a representative example for the period of April-May 2007.

Even this initial EKF implementation was able to successfully provide estimates of the aerosol size distribution using information from multiple observations. Additionally, it was able to simultaneously use both size-segregated and integrating observations. Based on these results, EKF appears to be a useful method to combine information from different instrumental sources into a physically consistent picture of the evolution of an aerosol population and its properties at a fixed measurement site. The next steps in the development of this method are to extend it to include other aerosol particle variables, e.g. refractive index and density, and to improve the error estimation.

We intend to provide an EKF based tool to the community that could be routinely used to obtain state estimates based on in-situ measurements from a variety of instruments.

Acknowledgements. This research has been partly funded by the Academy of Finland research project 133142. This work has been supported by European Commission 6th Framework program projects: EUCAARI, contract no. 036833-2 (EUCAARI) and EUSAAR, contract no. 026140 (EUSAAR). We also thank Pasi Aalto providing the measurements.

Edited by: W. Birmili

\section{References}

Aalto, P., Hämeri, K., Becker, E., Weber, R., Salm, J., Mäkelä, J. M., Hoell, C., O’Dowd, C. D., Karlsson, H., Hansson, H.-C., Väkevä, M., Koponen, I. K., Buzorius, G., and Kulmala, M.: Physical characterization of aerosol particles during nucleation events, Tellus, 53B, 344-358, 2001.
Anderson, T. L. and Ogren, J. A.: Determining aerosol radiative properties using the TSI 3563 Integrating Nephelometer, Aerosol. Sci. Technol., 29, 57-69, 1998.

Anderson, T. L., Covert, D. S., Marshall, S. F., Laucks, M. L, Charlson, R. J., Waggoner, A. P., Ogren, J. A., Caldow, R., Holm, R. L., Quant, F. R., Sem, G. J., Wiedensohler, A., Ahlquist, N. A., and Bates, T. S.: Performance characteristics of a high-sensitivity, three-wavelength total scatter/backscatter nephelometer, J. Atmos. Ocean. Tech., 13, 967-986, 1996.

Barber, P. W. and Hill, S. C.: Light scattering by particles: Computational methods, World Scientific Publishing, Singapore, 1990.

DeCarlo, P., Slowik, J. G., Worsnop, D. R., Davidovits, P., and Jimenez, J. L.: Particle morphology and density characterization by combined mobility and aerodynamic diameter measurements. Part 1: Theory, Aerosol. Sci. Technol., 38, 1185-1205, 2004.

Guyon, P., Boucher, O., Graham, B., Beck, J., Mayol-Bracero, O. L., Roberts, G. C., Maenhaut, W., Artaxo, P., and Andreae, M. O.: Refractive index of aerosol particles over the Amazon tropical forest during LBA-EUSTACH 1999, J. Aerosol Sci., 34, 883907, 2003.

Hand, J. L. and Kreidenweis, S. M.: A new methdod for retrieving particle refractive index and effective density from aerosol size distribution data, Aerosol Sci. Technol., 36, 1012-1026, 2002.

Hari, P. and Kulmala, M.: Station for Measuring EcosystemAtmosphere Relations (SMEAR II), Boreal Environ. Res., 10, 315-322, 2005.

Heintzenberg, J., Wiedensohler, A., Tuch, T. M., Covert, D. S., Sheridan, P., Ogren, J. A., Gras, J., Nessler, R., Kleefeld, C., Kalivitis, N., Aaltonen, V., Wilhelm, R. T., and Havlicek, M.: Intercomparisons and aerosol calibrations of 12 commercial integrating nephelometers of three manufacturers, J. Atmos. Ocean. Tech., 23, 902-914, 2006.

Hinds, W. C.: Aerosol Technology: Properties, behavior and measurement of airborne particles, New York, Wiley, 42-54, 1999.

Kaipio, J. and Somersalo, E.: Statistical and Computational Inverse Problems, Applied Mathematical Sciences, 160, SpringerVerlag, 339 pp., ISBN 0-387-22073-9, 2004.

Kalman, R. E.: A new approach to linear filtering and prediction problems, Trans. ASME J. Basic Eng., 82D, 35-45, 1960.

Kannosto, J., Virtanen, A., Lemmetty, M., Mäkelä, J. M., Keskinen, J., Junninen, H., Hussein, T., Aalto, P., and Kulmala, M.: Mode resolved density of atmospheric aerosol particles, Atmos. Chem. Phys., 8, 5327-5337, doi:10.5194/acp-8-5327-2008, 2008.

Korhonen, H., Lehtinen, K. E. J., and Kulmala, M.: Multicomponent aerosol dynamics model UHMA: model development and validation, Atmos. Chem. Phys., 4, 757-771, doi:10.5194/acp-4757-2004, 2004.

Kulmala, M., Lehtinen, K. E. J., and Laaksonen, A.: Cluster activation theory as an explanation of the linear dependence between formation rate of $3 \mathrm{~nm}$ particles and sulphuric acid concentration, Atmos. Chem. Phys., 6, 787-793, doi:10.5194/acp-6-787-2006, 2006.

Kulmala, M., Asmi, A., Lappalainen, H. K., Carslaw, K. S., Pöschl, U., Baltensperger, U., Hov, Ø., Brenquier, J.-L., Pandis, S. N., Facchini, M. C., Hansson, H.-C., Wiedensohler, A., and O'Dowd, C. D.: Introduction: European Integrated Project on Aerosol Cloud Climate and Air Quality interactions (EUCAARI) - integrating aerosol research from nano to global scales, Atmos. Chem. Phys., 9, 2825-2841, doi:10.5194/acp-9-2825-2009, 
2009.

Leppä, J., Anttila, T., Kerminen, V.-M., Kulmala, M., and Lehtinen, K. E. J.: Atmospheric new particle formation: real and apparent growth of neutral and charged particles, Atmos. Chem. Phys., 11, 4939-4955, doi:10.5194/acp-11-4939-2011, 2011.

McMurry, P. H.: A review of atmospheric aerosol measurements, Atmos. Environ., 34, 1959-1999, 2000.

Müller, T., Schladitz, A., Massling, A., Kaaden, N., Kandler, K., and Wiedensohler, A.: Spectral absorption coefficients and imaginary parts of refractive indices of Saharan dust during SAMUM-1, Tellus B, 61, 79-95, 2009.

Müller, T., Laborde, M., Kassell, G., and Wiedensohler, A.: Design and performance of a three-wavelength LED-based total scatter and backscatter integrating nephelometer, Atmos. Meas. Tech., 4, 1291-1303, doi:10.5194/amt-4-1291-2011, 2011.

Peters, T. M. and Leith, D.: Concentration measurement and counting efficiency of the aerodynamic article sizer 3321, J. Aerosol Sci., 34, 627-634, 2003.

Petzold, A., Rasp, K., Weinzierl, B., Esselborn, M., Hamburger, T., Dörnbrack, A., Kandler, K., Schütz, L., Knippertz, P., Fiebig, M., and Virkkula, A.: Saharan dust absorption and refractive index from aircraft-based observations during SAMUM 2006, Tellus B, 61, 118-130, 2009.

Pitz, M., Birmili, W., Schmid, O., Peters, A., Wichmann, H. E., and Cyrys, J.: Quality control and quality assurance for particle size distribution measurements at an urban monitoring station Augsburg, Germany, J. Environ. Monit., 10, 1017-1024, 2008.
Saarikoski, S., Mäkelä, T., Hillamo, R., Aalto, P., Kerminen, V.-M., and Kulmala, M.: Physico-chemical characterization and mass closure of size-segregated atmospheric aerosols in Hyytiälä, Finland, Boreal Environ. Res., 10, 385-400, 2005.

Tarantola, A.: Inverse Problem Theory and Methods for Model Parameter Estimation, Society for Industrial and Applied Mathematics, ISBN 0-89871-572-5, 2004.

Virkkula, A., Koponen, I. K., Teinilä, K., Hillamo, R., Kerminen, V.-M., and Kulmala, M.: Effective real refractive index of dry aerosols in the Antarctic boundary layer, Geophys. Res. Lett. 33, L06805, doi:10.1029/2005GL024602, 2006.

Virkkula, A., Backman, J., Aalto, P. P., Hulkkonen, M., Riuttanen, L., Nieminen, T., dal Maso, M., Sogacheva, L., de Leeuw, G., and Kulmala, M.: Seasonal cycle, size dependencies, and source analyses of aerosol optical properties at the SMEAR II measurement station in Hyytiälä, Finland, Atmos. Chem. Phys., 11, 4445-4468, doi:10.5194/acp-11-4445-2011, 2011.

Viskari, T., Asmi, E., Kolmonen, P., Vuollekoski, H., Petäjä, T., and Järvinen, H.: Estimation of aerosol particle number distributions with Kalman Filtering - Part 1: Theory, general aspects and statistical validity, Atmos. Chem. Phys., 12, 11767-11779, doi:10.5194/acp-12-11767-2012, 2012.

Volckens, J. A. E. and Peters, T. M.: Counting and particle transmission efficiency of the aerodynamic particle sizer, J. Aerosol Sci., 36, 1400-1408, 2005. 